\title{
AN INTERNATIONAL SYMPOSIUM ON INSTRUCTION IN THE MECHANICS OF FLUIDS
}

\section{SYMPOSIUM INTERNATIONAL SUR L'ENSEIGNEMENT DE LA MÉCANIQUUE DES FLUIDES}

\section{FLUID MECHANICS IN BRITISH EDUCATION}

BY A. M. BINNIE *

Fluid Mechanics remains the Cinderella among the subjects studied in British engineering schools. The reasons for this neglect were originally historical. The Institution of Civil Engineers was founded in 1818 to promote the development of non-military engineering defined in the words of its charter as the art of directing the great sources of power in Nature for the use and convenience of man'. Difficulties soon beset this simple ideal; and when the admission of Robert Stephenson was obstructed, his sympathizers started the Institution of Mechanical Engineers and elected him the first president. The fission process continued unchecked until very recently to the detriment of the advance of engineering knowledge. The reverse process of fusion has been found difficult to achieve because of vested interests. Thus after engineering penetrated in early-Victorian times into the more active bodies of university rank (King's College, London, and Glasgow University, 1840; University College, London, 1841; Trinity College, Dublin, 1842), it was natural to organize the laboratories into departments of civil, mechanical and later electrical engineering. In the first, the flow

\footnotetext{
* Trinity College, Cambridge.
}

of water was studied while, quite independently, hot and cold fluids were among the principal interests of the second. This arrangement is still widespread, although the artificial nature of the distinction between the two becomes more and more apparent. For example, some years back one of the principal named lectures at the 'Mechanicals' was entitled 'A century of tunnelling'. It demonstrated that tunnelling, which many would certainly regard as civil engineering, depended greatly on machinery, much of it air-operated.

A further division of the subject of fluid mechanics was brought about by the rapid development of flying in the war of 1914-18. Even universities were startled into action, and several departments of what was termed aeronautics were initiated. Some time elapsed before it was realized that much in this field was simply ordinary engineering made harder by a severe penalty on weight and could be treated in existing departments. There remained for the new laboratories the many problems posed by the relative motion of air, not artificially heated or cooled, round solid bodies. Thus in a single engincering school fluid mechanics may be taught unrelatedly in three different departments. The essential unity of the subject is obscured; and Reynolds' discovery, announced in 1883, of what Professor Lighthill has 
called 'the major simplifying feature of the subject' is still not fully employed. Solid mechanics does not labour under this disability. It is true that the dynamical part of the subject is treated by mechanical engineers. This, however, is relatively small and is quite overshadowed by the statical part, which under such labels as theory of structures and strength of materials is usually classed as civil engineering.

All told, the subject of fluid mechanics cannot be said to prosper. The aeronautical side is hampered by the contraction of the industry. The study of water flow remains unfashionable, even if described as hydrodynamics rather than hydraulics,-a term that conjures up the painstaking collection of unconnected results. For some years, at least one chair has remained unfilled for lack of a suitable candidate, and in 1961 Cambridge suppressed its undergraduate advanced course.

The organizational difficulties mentioned above are slowly being overcome, but local politics often prevent advances which are more than just perceptible when viewed over a period of, say, 20 years. Better progress may well result from the recent enormous expansion in higher education. In England sixteen new universities have been founded, in Scotland four, and one in both Wales and Northern Ireland. Some of these were formerly technical colleges that have now been upgraded, but others are brand-new organizations. Of the latter only a few at present possess engineering schools, but all are able to set out unhindered by prejudice and to try new and more logical arrangements of courses. These big developments have led to the creation of many new posts, involving a heavy demand on the staff and recent graduates of the existing universities. It is said, indeed, that for some years universities have been a sink of talent rather than a source. This period, however, has drawn to a close as the new departments have got under way. Nevertheless, engineering graduates continue to find themselves in a seller's market, and there is a rush for their services. An alternative source of good engineers hardly exists, for a university education is available for all who can benefit from it; the entry to the professional institutions now contains a high proportion of graduates. But in spite of the numerous openings that are available, engineering as a whole is not nearly as popular among undergraduates as natural science, though in both subjects the unfilled university places are to be counted in hundreds. Of the limited output, industry complains that it is not getting its fair share, and many graduates go abroad. For decades this country, without drawing attention to the fact, has attracted and retained many gifted people from overseas. The situation is now reversed, for conditions are better, or are believed to be better, in North America and elsewhere. 'This 'brain-drain', as it is termed, has excited widespread concern and has been reported on by a high-powered committee.

The statical part of fluid dynamics is small and easily taught. As G. H. Hardy once pointed out to me, this subject is unique (in the true sense of that abused word) in that it was invented and completed by the same man. On the other hand the dynamical part is hard and constantly extending. Available theories are usually inadequate, and much reliance has to be placed on experiment. Excellent films have been produced to help the student, but to learn thoroughly and retain his knowledge he should do the practical work himself. He must meet the realities of the subject and discover the fictions that some text-book writers copy from others. A couple of hours with a smoke tumnel and a variety of objects to put in it are more effective than attendance at many lectures. However, this method of acquiring knowledge is costly in time, space, staff and apparatus. A weak organization may be compelled to rely overmuch on lectures and drawing-office work, which are by far the cheapest methods of instruction. The inevitable result is that practical work is rarely adequate.

Another disability of an experimental subject can be seen in the examination room. The types of question on which it is easiest to obtain full marks (and which incidentally are easiest to mark) are the purely algebraical and numerical ones. Lower down comes the descriptive question, for in the heat of the moment even a good candidate may overlook a point for which the examiner is watching. Last come practical examinations, which are really a form of gambling, for questions are severely limited in number by difficulties with apparatus. They are troublesome to conduct and are commonly dispensed with, being replaced by a perusal of laboratory notebooks. However, since the course experiments usually require operation by pairs of students, too often by trios, this method seems unlikely to yield accurate results; at the most it should be regarded as a qualifying test. The more sagacious candidates and their advisers are thus aware that success is most readily achieved by choosing subjects that lend themselves to calculation. Fluid mechanics comes badly out of this test. In contrast we may take the study of structures. Here most of the theories are amply accurate enough for engineering purposes; it requires refined apparatus to detect errors in, say, the theory of bending.

Fluid dynamics, unlike elementary mechanics of solids, is not taught in secondary schools, but it may be studied at a wide range of centres of higher education in addition to engineering departments at universities. On the one hand, there are numerous technical colleges often with courses arranged to suit the needs of local industry. On the other, many university departments of applied mathematics include fluid mechanics among their interests. Although in the darker recesses of some it is to be feared that the subject is used merely as a hook on which to hang elegant analysis, yet others flourish exceedingly with more research students engaged in fluid mechanics than is the neighbouring departments of engineering. 